\title{
PENERAPAN METODE SUPERVISED CLASSIFICATION MAXIMUM LIKELIHOOD PADA CITRA SATELIT LANDSAT UNTUK MEMETAKAN PERUBAHAN TUTUPAN LAHAN DI TAMAN NASIONAL BUKIT BARISAN SELATAN (TNBBS)
}

\section{Application of Supervised Classification Maximum Likelihood Method in Landsat Satellite Image to Map the Change of Land Cover at the Bukit Barisan Selatan National Park (BBSNP)}

\author{
Bulkis Kanata $^{[1]}$, Muhamad Syamsu Iqbal ${ }^{[1]}$, Ramdayanti ${ }^{[2]}$ \\ [1] Jurusan Teknik Elektro, Universitas Mataram. Jl. Majapahit 62, Mataram, 83125 Lombok, Indonesia \\ ${ }^{[2]}$ Mahasiswa Jurusan Elektro S1, Universitas Mataram. Jl. Majapahit 62, Mataram, 83125 Lombok, Indonesia \\ Email: uqikanata@unram.ac.id
}

\begin{abstract}
ABSTRAK
Taman nasional merupakan kawasan pelestarian alam yang mempunyai fungsi sebagai perlindungan sistem penyangga kehidupan, pengawetan keanekaragaman jenis tumbuhan dan satwa serta ekosistemnya yang dikelola dengan sistem zonasi, yang terdiri dari zona inti, zona pemanfaatan, dan zona lain sesuai keperluan (Undang-undang No. 5 Tahun 1990). Namun sejauh ini masih sering muncul permasalahan yang terjadi hampir disetiap taman nasional, seperti perburuan satwa liar, illegal loging, perambahan, pencurian kayu/tumbuhan langka dan tata batas kawasan. Salah satu taman nasional yang ada di Indonesia yang tidak luput dari permasalahan adalah Taman Nasional Bukit Barisan Selatan. Penelitian ini dilakukan untuk mengetahui perubahan tutupan lahan yang terjadi di TNBBS. Setelah dilakukan penelitian dengan menggunakan software ArcGIS dengan metode supervised maximum likelihood classification diketahui bahwa dalam kurun tahun 2015 sampai 2018 terjadi peningkatan luas pemukiman sebesar $0,32 \%$ dan penurunan luas vegetasi tinggi (kawasan hutan) hingga 7,99\%. Lahan terbuka mengalami penurunan luas $0,79 \%$, lahan pertanian mengalami penurunan hingga $1,12 \%$, tutupan lahan berupa rumput/semak meningkat hingga $4,58 \%$ dan tutupan lahan vegetasi sedang meningkat hingga $5,03 \%$.
\end{abstract}

Kata kunci: Taman Nasional Bukit Barisan Selatan, perubahan tutupan lahan, ArcGIS, Maximum Likelihood Clasification.

\section{ABSTRACT}

A national park is a natural conservation area that has a function as protection of life support systems, preservation of diversity of plant and animal species and their ecosystems which are managed by a zoning system, which consists of a core zone, a utilization zone, and other zones as required (Law No.5 1990). However, so far there are still problems that occur in almost every national park, such as hunting for wild animals, illegal logging, encroachment, theft of rare wood/plants and zoning of areas. One of the national parks in Indonesia that is not free from problems is the Bukit Barisan Selatan National Park. This research was conducted to determine changes in land cover that occurred in BBSNP. After conducting research using ArcGIS software with the supervised maximum likelihood classification method, it is known that from 2015 to 2018 there was an increase in residential area by $0.32 \%$ and a decrease in high vegetation area (forest area) by $7.99 \%$. Open land has decreased in area by $0.79 \%$, agricultural land has decreased by $1.12 \%$, land cover in the form of grass / shrubs has increased by $4.58 \%$ and land cover for vegetation is increasing up to $5.03 \%$.

Key words: Bukit Barisan Selatan National Park Change of Land Cover, ArcGIS, Maximum Likelihood Clasification

$\begin{array}{cl}\text { PENDAHULUAN } & \text { fungsi sebagai perlindungan sistem } \\ \text { Taman nasional merupakan } & \text { penyangga kehidupan, pengawetan } \\ \text { kawasan pelestarian alam yang memiliki } & \begin{array}{l}\text { keanekaragaman jenis satwa dan } \\ \text { tumbuhan serta ekosistemnya yang }\end{array}\end{array}$


dikelola dengan sistem zonasi, yaitu terdiri dari zona inti, zona pemanfaatan, dan zona lain sesuai keperluan (Undang-undang No. 5 Tahun 1990).

Taman Nasional Bukit Barisan Selatan merupakan salah satu dari tiga taman nasional di Sumatera yang merupakan prioritas tertinggi bagi unit konservasi harimau, dan taman nasional yang memiliki ekosistem hutan dataran rendah terbesar pada hutan hujan tropis di Asia Tenggara [1]. Sekitar November 2019, laporan yang dihimpun Seksi Konservasi Wilayah II Lahat Balai Konservasi Sumber Daya Alam (BKSDA) Sumatera Selatan, kawasan di sekitar Kantong Harimau Bukit Dingin dan Jambul Nanti Patah yang berada di dua daerah, yakni Pagar Alam dan Lahat, menjadi lokasi harimau-harimau muncul dan menyerang warga. Keluarnya harimau dari habitatnya dan menyerang manusia dapat disebabkan karena banyak pembukaan lahan baru dalam habitat harimau yang membuat rantai makanan satwa terputus.Bertambahnya wilayah perkebunan, pembukaan lahan dan pembukaan area pertambangan membuat satwa liar ini merasa terancam akan kehadiran manusia [2]. Dengan memperhatikan hal tersebut maka perlu diadakan penelitian tentang pemetaan tutupan lahan di Taman Nasional Bukit Barisan Selatan (TNBBS).

Dengan menerapkan Metode Supervised Classification Maximum Likelihood untuk analisis citra satelit terhadap pemetaan tutupan lahan di Taman Nasional Bukit Barisan Selatan (TNBBS), diharapkan dapat memberikan informasi mengenai tutupan lahan yang ada di TNBBS yang sesuai dengan objek aslinya, serta dapat memberi informasi mengenai metode klasifikasi terbimbing yang dapat digunakan untuk memetakan tutupan lahan dan dapat dijadikan sebagai bahan evaluasi, rujukan atau pertimbangan oleh pihak taman nasional dalam kegiatan pengelolaan kawasan dan pengambilan kebijakan.

\section{TINJAUAN PUSTAKA}

Penelitian yang dilakukan oleh [3] tentang perbandingan klasifikasi Maximum Likelihood dan Object Oriented pada pemetaan tutupan lahan/penggunaan lahan studi kasus Gayo Lues NAD, HTI PT. Wirakarya Sakti Jambi dan Tanam
Nasional Lore Lindu Sulawesi Tengah. Data yang digunakan pada penelitian tersebut adalah citra satelit Landsat dan citra satelit Quicbird. Penelitian ini melakukan perbandingan antara metode terbimbing Maximum Likelihood dan metode Object Oriented. Pembuatan training area didasarkan pada contoh jenis tutupan lahan/pengunaaan lahan yang telah diketahui saat proses ground check. Uji akurasi dari kedua metode ini dilakukan dengan menggunakan Confusion Matrix dengan melihat nilai akurasi pengguna, akurasi pembuat, akurasi keseluruhan dan nilai kappa. Proses klasifikasi metode MLC pada penelitian tersebut dilakukan di perangkat lunak ERDAS Imagine versi 8.7.

Penelitian yang dilakukan oleh [4] tentang identifikasi karakteristik dan pemetaan klasifikasi tutupan lahan menggunakan citra Landsat 8 (OLI) di Kabupaten Bogor. Data yang digunakan pada penelitian tersebut adalah citra Landsat 8 (OLI). Proses klasifikasi citra menggunakan metode terbimbing yaitu Maximum Likelihood menggunakan software Erdas Imagine 9.1, dengan hasil klasifikasi diperoleh 15 kelas tutupan lahan di Kabupaten Ogan Komering 17 Ilir. Kelas tutupan lahan yang dihasilkan yaitu hutan pinus, sawah baru tanam, kebun karet, lahan terbangun, awan, bayangan awan, badan air, lahan terbuka, lapangan terbang, kebun buah, perkebunan sawit, hutan tutupan rapat, semak belukar, sawah siap panen, dan kebun campuran. Analisis akurasi pada penelitian ini yaitu menggunakan confusion matrix, analisis akurasi memberikan ketelitian yang baik dengan nilai overall accuracy sebesar $92.18 \%$ dan kappa accuracy sebesar $90.61 \%$.

Penelitian oleh [5] melakukan perbandingan antara dua metode klasifikasi terbimbing yaitu Maximum Likelihood dan Minimum Distance. Data yang digunakan dalam penelitian ini adalah data citra satelit ALOS AVNIR-2 tahun 2009. Hasil dari perbandingan dari segi uji akurasi kedua metode, didapati bahwa hasil akurasi metode Maximum Likelihood lebih unggul dari pada metode Minimum Distance, dengan nilai overall accuracy metode Maximum Likelihood sebesar $93,60 \%$. 


\section{a. Penginderaan Jauh}

Penginderaan jauh merupakan suatu penggabungan dari suatu ilmu serta seni yang digunakan untuk mendapatkan informasi mengenai suatu objek, daerah, atau fenomena dengan melakukan analisis data yang diperoleh dengan suatu alat tanpa harus bersentuhan langsung dengan objek yang sedang dikaji [6]. Menurut [7] menjelaskan bahwa penginderaan jauh adalah proses untuk mendapatkan informasi dari suatu sifat objek atau fenomena tertentu dengan cara tidak terjadi kontak langsung dengan objek yang dikaji tetapi dengan menggunakan alat perekam. Banyak para ilmuwan yang mendefinisikan penginderaan jauh dengan bahasa yang berbeda, seperti yang disampaikan oleh [8] penginderaan jauh adalah teknik dalam mendapatkan informasi tentang suatu objek atau lingkungan dari jarak yang jauh dan tidak bersentuhan langsung dengan objek yang dikaji.

\section{b. Citra Landsat}

Citra Landsat 8 itu sendiri adalah satelit yang bertugas mengobservasi bumi dan merupakan hasil kerja sama antara National Aeronautics and Space Administration (NASA) dan juga U.S Geographical Survey (USGS). Satelit Landsat 8 memiliki 2 sensor yaitu Operational Land Imager (OLI) dan Thermal Infrared Sensor (TIRS), dengan kedua sensor tersebut Landsat 8 dapat terbang pada ketinggian $705 \mathrm{~km}$ dari permukaan bumi dan memiliki area rekam seluas 170 $\mathrm{km} \times 183 \mathrm{~km}$. Satelit Landsat 8 didesain untuk dapat beroperasi selama 5 tahun. Citra satelit Landsat 8 ini dalam melakukan liputan pada area yang sama memerlukan waktu 16 hari sekali dan untuk mengorbit bumi memerlukan waktu 99 menit. Satelit Landsat 8 mempunyai 11 saluran/band yang dimana 9 band terdapat pada sensor Operational Land Imager (OLI) dan 2 band lainnya berada pada sensor Thermal Infrared Sensor (TIRS) [9].

\section{c. Klasifikasi Penutupan Lahan}

Menurut [10] penutupan Iahan merupakan gambaran nyata tentang objek yang menutupi lahan, dengan tidak mencampurkan dengan kegiatan-kegiatan yang ada di dalam objek tersebut. Sistem klasifikasi penutupan lahan merupakan suatu cara untuk menyajikan data sebagai acuan dalam proses interpretasi dengan cara mengelompokannya. Salah satu hal penting yang harus diketahui, dalam hal menentukan keberhasilan pemetaan penutupan lahan tersebut terletak pada pemilihan sistem klasifikasi yang tepat.

\section{d. ArcGIS}

ArcGis merupakan sotware berbasis GIS (Geographic Information System) yang dikembangkan oleh Environment Science \& Research Institue (ESRI). Produk utama Arcgis terdiri dari tiga komponen utama yaitu: ArcView (fungsinya sebagai pengelola data komprehensif, pemetaan dan analisis), ArcEditor (fungsinya sebagai editor pada data spasial) dan Arclnfo (yaitu fitur yang menyediakan beberapa fungsi di dalam GIS yaitu meliputi keperluan analisa dari fitur Geoprocessing). Dimana pada versi terbarunya, ArcGis Deskstop mempunyai beberapa fitur yaitu ArcMap, ArcGlobe, ArcCatalog dan ArcScene.

\section{e. Klasifikasi Citra}

Menurut [11] klasifikasi adalah tahap pengelompokkan piksel_piksel dari suatu citra ke dalam kategori-kategori yang telah ditetapkan dengan melihat nilai kecerahan (Digital Number) dari suatu citra. Analisis citra digital adalah tahapan pengurutan, penyusunan dan pengelompokan pikselpiksel dari suatu citra digital multispektral ke dalam beberapa kelas berdasarkan kategori objek [12].

Menurut [12] klasifikasi terbimbing (supervised classification) adalah metode tahapan yang dibutuhkan untuk mentransformasikan data citra satelit multispektral ke dalam kelas-kelas unsur spasial. Ada dua klasifikasi terbimbing yaitu metode Minimum Distance Classification (MDC) dan Maximum Likelihood Classification (MLC).

f. Maximum Likelihood Classifiction (MLC) Metode Maximum Likelihood Classification didasarkan pada nilai piksel yang sama dan pengenalan pada citra. Satu karekteristik dengan sebaran normal bisa mewakili setiap piksel dalam kelasnya. Maximum Likelihood Classification adalah klasifikasi yang melakukan penggolongan parameter dengan mengasumsikan distribusi spektralnya normal atau mendekati normal pada masing-masing karakteristik yang menarik. Kemungkinan yang sama di antara kelas juga diasumsikan. Maximum Likelihood 
Classification memerlukan data sampel pelatihan spektral perwakilan untuk tiap kelas secara akurat dengan cara memperkirakan nilai dari mean vektor dan kovarian matriks yang diperlukan oleh algoritma klasifikasi. Jika sampel pelatihan terbatas atau tidak representatif maka estimasi elemen yang tidak akurat sering kali akan menghasilkan klasifikasi yang buruk [13].

Proses klasifikasi menggunakan metode MLC ini didasarkan pada perhitungan densitas probabilitas untuk tiap kategori tutupan lahan. Perhitungan probabilitas atau yang dikenal dengan likelihood ini bertujuan untuk menemukan sebuah piksel dari suatu kelas, yang dapat dijelaskan dari persamaan berikut:

$$
P(i \mid x)=\frac{P(x \| i) P(i)}{P(x)}
$$

Dimana: $P(i \mid x), P(x \mid i), P(i)$ dan $P(x)$ adalah probabilitas bersyarat dari suatu kelas i yang dihitung dengan ketetapan bahwa vektor $\mathrm{x}$ tanpa syarat, probabilitas bersyarat dari vektor $x$ yang dihitung dengan kelas yang tanpa syarat, probabilitas dari suatu kelas i yang muncul dari sebuah citra dan probabilitas dari vektor $\mathrm{x}$.

\section{g. Training Sample}

Pengambilan training sample sangat diperlukan karena klasifikasi yang akan dilakukan adalah klasifikasi terbimbing, yang perlu diperhatikan dalam pengambilan training sample adalah jumlah dari poligon sampel yang diambil, minimal 3 poligon untuk setiap jenis tutupan lahan. Dalam satu poligon tersebut minimal terdapat 9 piksel yang yang memiliki kemiripan dan keseragaman warna dan rona sesuai dengan titik hasil ground check [6].

\section{METODOLOGI}

\section{a. Tempat Penelitian}

Penelitian ini dilakukan di kawasan Kota Pagar Alam, Taman Nasional Bukit Barisan Selatan, Sumatera Selatan. Kota Pagar Alam memiliki luas sekitas $633,66 \mathrm{~km}^{2}$ dan jumlah penduduk 126.181 jiwa serta termasuk ke dalam kawasan zona inti TNBBS. Adapun batas utara penelitian yaitu kecamatan Jerai dan Panjar Bulan. Batas barat yaitu Gunung Dempo, batas selatan yaitu kawasan hutan Gunung Patah dan batas timur yaitu jalan lintas antar Pagar
Alam dan Lahat. Berikut adalah peta lokasi penelitian dengan menggunakan teknologi penginderaan jauh sebagaimana terlihat pada Gambar 1.

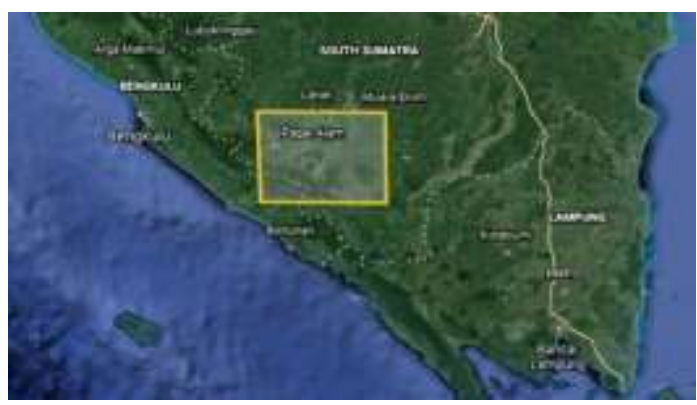

Gambar 1. Peta lokasi penelitian

b. Alat dan Bahan

1. Laptop

2. ArcGis 10.7

3. Microsoft Office 2015

4. Google Earth Pro

5. Citra satelit Landsat $8 \mathrm{OLI}$ dari tahun 2015 pada tanggal 3 Juli, 2016 pada tanggal 6 Agustus, 2017 pada tanggal 6 Juni, dan 2018 pada tanggal 24 Mei.

\section{c. Pengolahan Data Citra}

\section{c.1. Komposit Citra}

Proses penggabungan (komposit) band ini dapat dilakukan dengan menggunakan aplikasi Arcmap untuk proses klasifikasi. Kombinasi band yang dipilih yaitu 7-5-4. Kombinasi band 7-5-4 merupakan gabungan dari band 7 (SWIR2), band 5 (NIR) dan band 4 (red).

\section{c.2. Penajaman Citra}

Penajaman citra dilakukan agar lebih memudahkan interpretasi visual dan pemahaman terhadap suatu citra. Teknik penajaman citra digunakan untuk perbaikan citra, meningkatkan perubahan skala keabuan nilai kecerahan piksel dalam hal kualitas cetak fotografik untuk interpretasi dalam pengolahan citra. Langkah penajaman data citra landsat yaitu dengan menambahkan band 8 sebagai data pankromatik dengan resolusi $15 \mathrm{~m} \times 15 \mathrm{~m}$.

\section{c.3. Pembuatan Aol (Area of Interest)}

Pembuatan Aol (Area of Interest) dilakukan pada aplikasi Arcmap agar analisa data terpusat pada objek atau daerah yang akan diteliti. Adapun langkahlangkah yang dapat dilakukan dengan memanfaatkan toolbar draw untuk menggambar grafik pada daerah yang akan 
diteliti pada citra landsat dalam bentuk persegi kemudian pilih area yang akan diteliti. Setelah area ditentukan, selanjutnya export dari draw ke SHP dengan Convert Graphics To Features.

\section{c.4. Penentuan Area Contoh (Training Area)}

Training Area dilakukan berdasarkan data yang sudah diperoleh dari hasil interpretasi citra secara visual, peta rupa bumi dan pengambilan titik objek di lapangan. Pengambilan titik objek di lapangan harus mewakili satu kelas atau kategori tutupan lahan. Titik yang menjadi area contoh (training area) kemudian diambil ke dalam beberapa piksel pada setiap kelas tutupan lahannya dan ditentukan lokasinya pada citra komposit untuk menganalisis informasi statistik yang diperoleh dari lapangan. Training area diperlukan pada setiap kelas yang akan dibuat, serta diambil dari areal yang cukup homogen.

\section{c.5. Klasifikasi tutupan lahan}

Klasifikasi terbimbing (supervised classification) adalah metode yang diperlukan untuk mentransformasikan data citra multi-spektral ke dalam kelas-kelas unsur spasial (Prahasta 2008). Metode yang digunakan dalam penelitian ini menggunakan metode peluang maksimum (maximum likelihood classifier). Metode peluang maksimum ini mempertimbangkan nilai rata-rata dan keragaman antar kelas dan saluran (kovariansi) (Lillesand et al. 1990). Nilai pada metode maximum likelihood didasarkan pada nilai piksel yang sama atau identik pada citra.

\section{c.6. Perhitungan Luas Tutupan Lahan}

Perubahan lahan dapat diidentifikasi dengan membandingkan data tutupan lahan tahun 2015, tahun 2016, tahun 2017 dan data tutupan lahan tahun 2018. Salah satu cara yang bisa dilakukan adalah dengan menghitung luasan setiap jenis tutupan lahan pada fungsi calculate geometry pada arcmap.

\section{c.7. Analisis Perubahan Luas Tutupan Lahan}

Hasil perhitungan luas tutupan lahan tiap seri tahun pada tabel atribut kemudian di export dan disimpan dalam bentuk Excel Workbook agar selanjutnya dapat diolah dan dianalisis bersama untuk mengetahui perubahan luas tutupan lahan dari tahun 2015 sampai 2018. d. Diagram Alir Penelitian

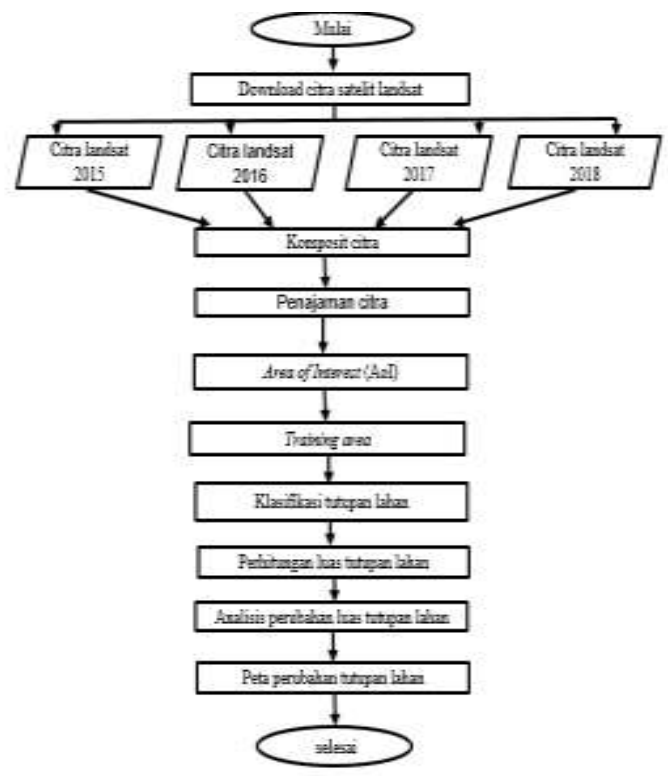

Gambar 2. Diagram alir penelitian

\section{HASIL DAN PEMBAHASAN}

a. Tutupan Lahan TNBBS Tahun 2015

Hasil dari pengolahan citra pada tahun 2015 didapat data berupa klasifikasi mengenai tipe tutupan lahan serta luasan masing-masing jenis tutupan lahan.

Tabel 1. Tutupan Lahan TNBBS Tahun 2015

\begin{tabular}{|c|c|c|c|c|}
\hline No & $\begin{array}{c}\text { Tutupan } \\
\text { Lahan } 2015 \\
\end{array}$ & $\begin{array}{c}\text { Jumlah } \\
\text { piksel }\end{array}$ & $\begin{array}{c}\text { Luas } \\
(\mathrm{Ha})\end{array}$ & $\%$ \\
\hline 1 & Pemukiman & 42.645 & 959,53 & $1,5 \%$ \\
\hline 2 & $\begin{array}{c}\text { Lahan } \\
\text { Terbuka }\end{array}$ & 100.929 & $2.270,91$ & $3,56 \%$ \\
\hline 3 & Pertanian & 199.624 & $4.469,04$ & $7,01 \%$ \\
\hline 4 & $\begin{array}{c}\text { Rumput / } \\
\text { semak }\end{array}$ & 1.228 .390 & $27.616,29$ & $43,34 \%$ \\
\hline 5 & $\begin{array}{l}\text { Vegetasi } \\
\text { Sedang }\end{array}$ & 841.199 & $18.926,99$ & $29,70 \%$ \\
\hline 6 & $\begin{array}{c}\text { Vegetasi } \\
\text { tinggi }\end{array}$ & 420.873 & $9.469,65$ & $14,86 \%$ \\
\hline & Tutal & 2.833 .830 & $63.712,41$ & $100,0 \%$ \\
\hline
\end{tabular}

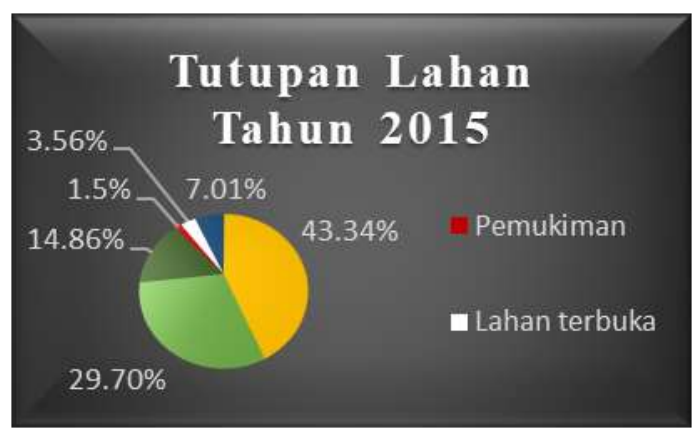

Gambar 3. Diagram Tutupan Lahan Tahun 2015 
Berdasarkan diagram pada gambar 3 , tipe penutupan lahan yang paling luas pada tahun 2015 adalah penutupan lahan rumput/semak dengan luasan total $27.616,29$ ha atau $43,34 \%$ dari seluruh kawasan, sedangkan penutupan lahan yang paling sedikit adalah pemukiman seluas 959,53 ha atau 1,5\% dari seluruh kawasan. Pada tahun 2015 luas lahan terbuka seluas $2.270,91$ ha atau $3,56 \%$, pertanian seluas $4.469,04$ ha atau $7,01 \%$, vegetasi sedang seluas $18.926,99$ ha atau $29,70 \%$ dan vegetasi tinggi seluas 9.469,65 ha atau $14,86 \%$. Peta tutupan lahan tahun 2015 dapat dilihat pada Gambar 4.

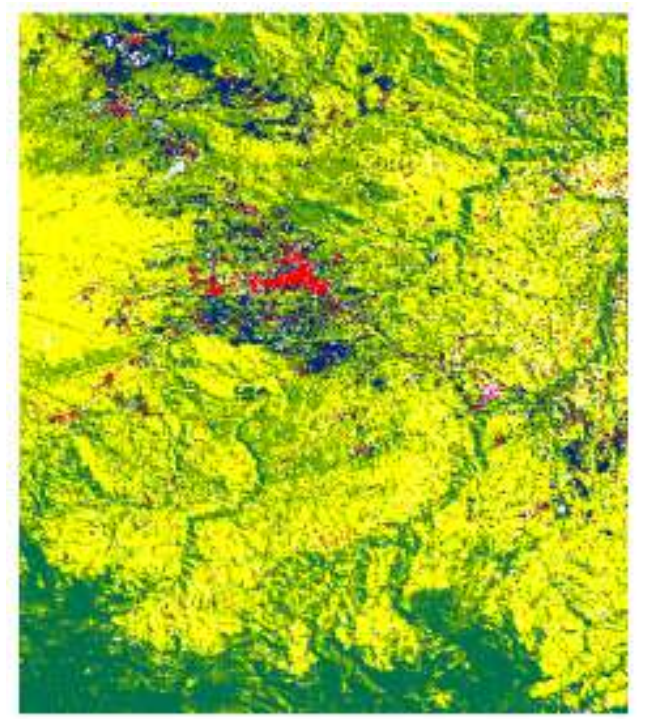

Gambar 4. Peta Tutupan Lahan TNBBS Tahun 2015

b. Tutupan Lahan TNBBS Tahun 2016

Hasil dari pengolahan citra pada tahun 2016 didapat data berupa klasifikasi mengenai tipe tutupan lahan serta luasan masing-masing jenis tutupan lahan.

Tabel 2. Tutupan Lahan TNBBS Tahun 2016

\begin{tabular}{|c|c|c|c|c|}
\hline No & $\begin{array}{c}\text { Tutupan } \\
\text { Lahan 2016 }\end{array}$ & $\begin{array}{c}\text { Jumlah } \\
\text { piksel }\end{array}$ & $\begin{array}{c}\text { Luas } \\
\text { (Ha) }\end{array}$ & $\%$ \\
\hline 1 & Pemukiman & 44.710 & $1.005,99$ & $1,57 \%$ \\
\hline 2 & $\begin{array}{c}\text { Lahan } \\
\text { Terbuka }\end{array}$ & 76.352 & $1.717,94$ & $2,69 \%$ \\
\hline 3 & Pertanian & 142.326 & $3.202,34$ & $5,02 \%$ \\
\hline 4 & $\begin{array}{c}\text { Rumput / } \\
\text { semak }\end{array}$ & 1.428 .443 & $32.117,48$ & $50,42 \%$ \\
\hline 5 & $\begin{array}{c}\text { Vegetasi } \\
\text { sedang }\end{array}$ & 783.599 & $17.608,48$ & $27,64 \%$ \\
\hline 6 & $\begin{array}{c}\text { Vegetasi } \\
\text { tinggi }\end{array}$ & 358.330 & $8.060,18$ & $12,66 \%$ \\
\hline & Total & 2.833 .830 & $63.712,41$ & $100,00 \%$ \\
\hline
\end{tabular}

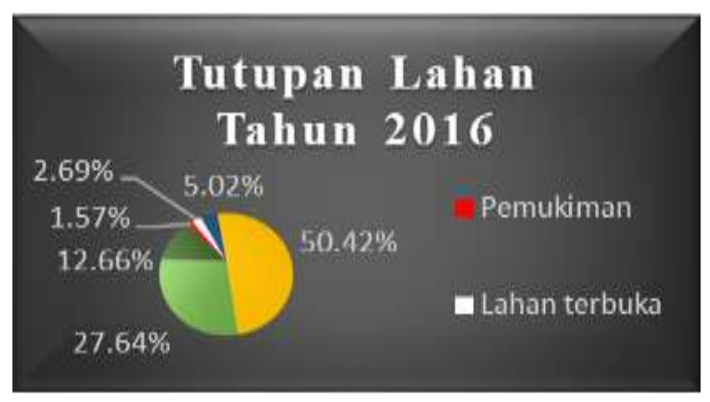

Gambar 5, Diagram Tutupan Lahan Tahun 2016

Berdasarkan diagram pada Gambar 5 , tipe penutupan lahan yang paling luas pada tahun 2016 adalah penutupan lahan rumput / semak dengan luasan total $32.117,48$ ha atau $50,42 \%$ dari seluruh kawasan, sedangkan penutupan lahan yang paling sedikit adalah pemukiman seluas $1.005,99$ ha atau $1,57 \%$ dari seluruh kawasan. Pada tahun 2016 luas lahan terbuka seluas $1.717,94$ ha atau $2,69 \%$, pertanian seluas $3.202,34$ ha atau $5,02 \%$, vegetasi sedang seluas $17.608,48$ ha atau $27,64 \%$ dan vegetasi tinggi seluas $8.060,18$ ha atau $12,66 \%$. Peta tutupan lahan tahun 2016 dapat dilihat pada Gambar 6.

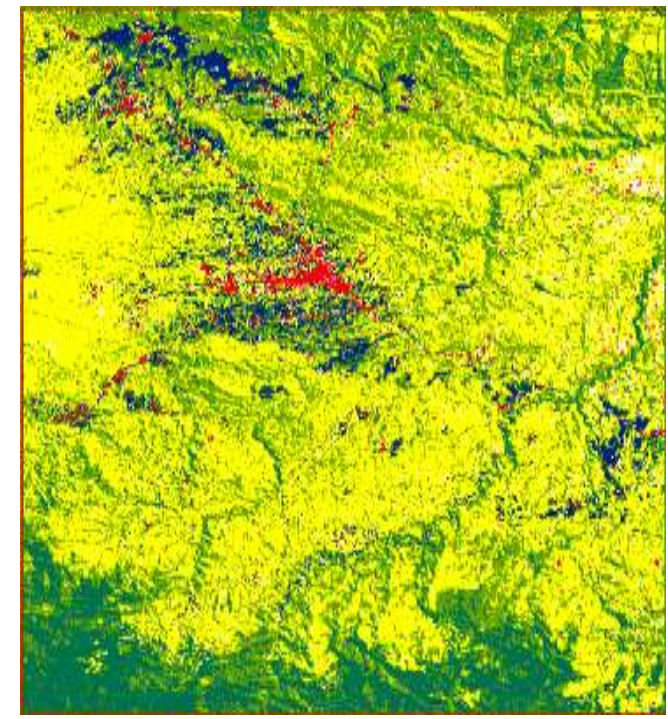

Gambar 6. Peta Tutupan Lahan TNBBS Tahun 2016

c. Tutupan Lahan TNBBS Tahun 2017

Hasil dari pengolahan citra pada tahun 2017 didapat data berupa klasifikasi mengenai tipe tutupan lahan serta luasan masing-masing jenis tutupan lahan. 
Tabel 3. Tutupan Lahan TNBBS Tahun 2017

\begin{tabular}{|c|c|c|c|c|}
\hline No & $\begin{array}{c}\text { Tutupan } \\
\text { Lahan } \\
2017 \\
\end{array}$ & $\begin{array}{c}\text { Jumlah } \\
\text { piksel }\end{array}$ & $\begin{array}{l}\text { Luas } \\
(\mathrm{Ha})\end{array}$ & $\%$ \\
\hline 1 & Pemukiman & 48.215 & $1.084,84$ & $1,70 \%$ \\
\hline 2 & $\begin{array}{l}\text { Lahan } \\
\text { terbuka }\end{array}$ & 141.368 & $3.158,30$ & $4,95 \%$ \\
\hline 3 & Pertanian & 89.303 & $2.009,32$ & $3,14 \%$ \\
\hline 4 & $\begin{array}{l}\text { Rumput/ } \\
\text { semak }\end{array}$ & 1.565 .414 & $35.199,32$ & $55,20 \%$ \\
\hline 5 & $\begin{array}{l}\text { Vegetasi } \\
\text { sedang }\end{array}$ & 689.739 & $15.519,14$ & $24,45 \%$ \\
\hline 6 & $\begin{array}{l}\text { Vegetasi } \\
\text { tinggi }\end{array}$ & 299.621 & $6.741,49$ & $10,56 \%$ \\
\hline & Total & 2.833 .830 & $63.712,41$ & $100,00 \%$ \\
\hline
\end{tabular}

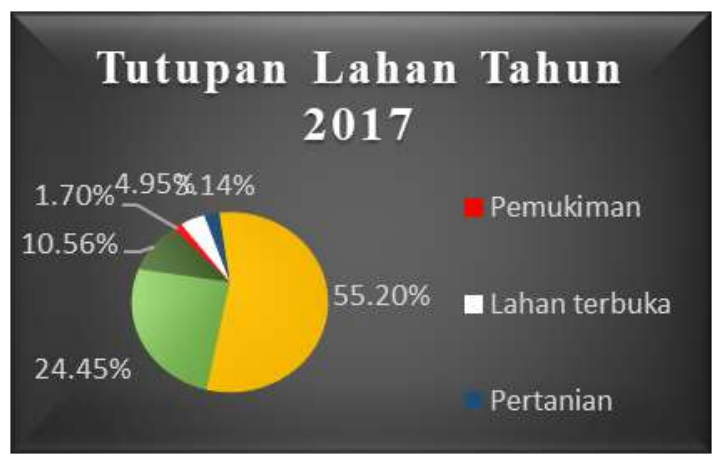

Gambar 7. Diagram Tutupan Lahan Tahun 2017

Berdasarkan diagram pada gambar 7, tipe penutupan lahan yang paling luas pada tahun 2017 adalah penutupan lahan rumput / semak dengan luasan total $35.199,32$ ha atau $55,20 \%$ dari seluruh kawasan, sedangkan penutupan lahan yang paling sedikit adalah pemukiman seluas $1.084,84$ ha atau $1,70 \%$ dari seluruh kawasan.

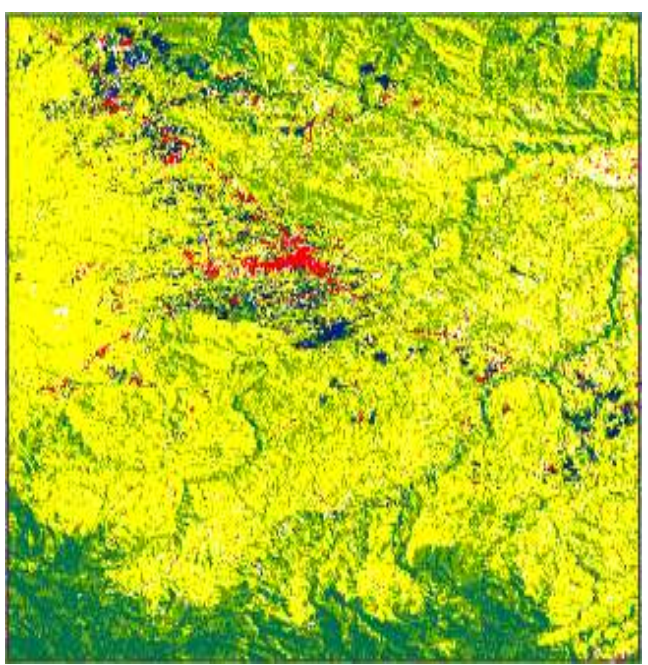

Gambar 8. Peta Tutupan Lahan TNBBS Tahun 2017
Pada tahun 2017 luas lahan terbuka seluas $3.158,30$ ha atau $4,95 \%$, pertanian seluas $2.009,32$ ha atau $3,14 \%$, vegetasi sedang seluas $15.519,14$ ha atau $24,45 \%$ dan vegetasi tinggi seluas $6.741,49$ ha atau 10,56\%. Peta tutupan lahan tahun 2017 dapat dilihat pada Gambar 8.

d. Tutupan Lahan TNBBS Tahun 2018

Hasil pengolahan citra pada tahun 2018 diperoleh data berupa klasifikasi mengenai tipe tutupan lahan serta luasan masing-masing jenis tutupan lahan.

Tabel 4. Tutupan Lahan TNBBS Tahun 2018

\begin{tabular}{|c|c|c|c|c|}
\hline No & $\begin{array}{c}\text { Tutupan } \\
\text { Lahan } 2018\end{array}$ & $\begin{array}{c}\text { Jumlah } \\
\text { piksel }\end{array}$ & $\begin{array}{r}\text { Luas } \\
\text { (Ha) }\end{array}$ & $\%$ \\
\hline 1 & Pemukiman & 51.509 & $1.158,97$ & $1,82 \%$ \\
\hline 2 & $\begin{array}{l}\text { Lahan } \\
\text { terbuka }\end{array}$ & 78.484 & $1.765,91$ & $2,77 \%$ \\
\hline 3 & Pertanian & 166.594 & $3.725,87$ & $5,89 \%$ \\
\hline 4 & $\begin{array}{r}\text { Rumput / } \\
\text { semak }\end{array}$ & 1.308 .853 & $29.449,20$ & $47,92 \%$ \\
\hline 5 & $\begin{array}{r}\text { Vegetasi } \\
\text { sedang }\end{array}$ & 984.122 & $22.120,26$ & $34,73 \%$ \\
\hline 6 & $\begin{array}{c}\text { Vegetasi } \\
\text { tinggi }\end{array}$ & 244.097 & $5.492,20$ & $6,87 \%$ \\
\hline & Total & 2.833 .830 & $63.712,41$ & $100,00 \%$ \\
\hline
\end{tabular}

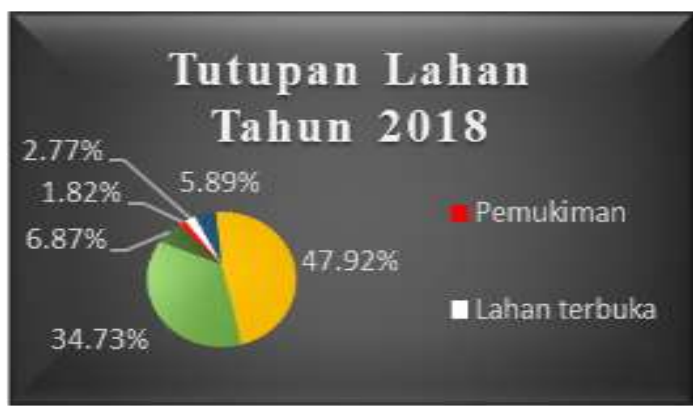

Gambar 9. Diagram Tutupan Lahan Tahun 2018

Berdasarkan diagram pada gambar 9 , tipe penutupan lahan yang paling luas pada tahun 2018 adalah penutupan lahan rumput / semak dengan luasan total $29.449,20$ ha atau $47,92 \%$ dari seluruh kawasan, sedangkan penutupan lahan yang paling sedikit adalah pemukiman seluas $1.158,97$ ha atau $1,82 \%$ dari seluruh kawasan. Pada tahun 2017 luas lahan terbuka seluas $1.765,91$ ha atau $2,77 \%$, pertanian seluas $3.725,87$ ha atau $5,89 \%$, vegetasi sedang seluas $22.120,26$ ha atau $34,73 \%$ dan vegetasi tinggi seluas $5.492,20$ ha atau $6,87 \%$. Peta tutupan lahan tahun 2017 dapat dilihat pada Gambar 10. 


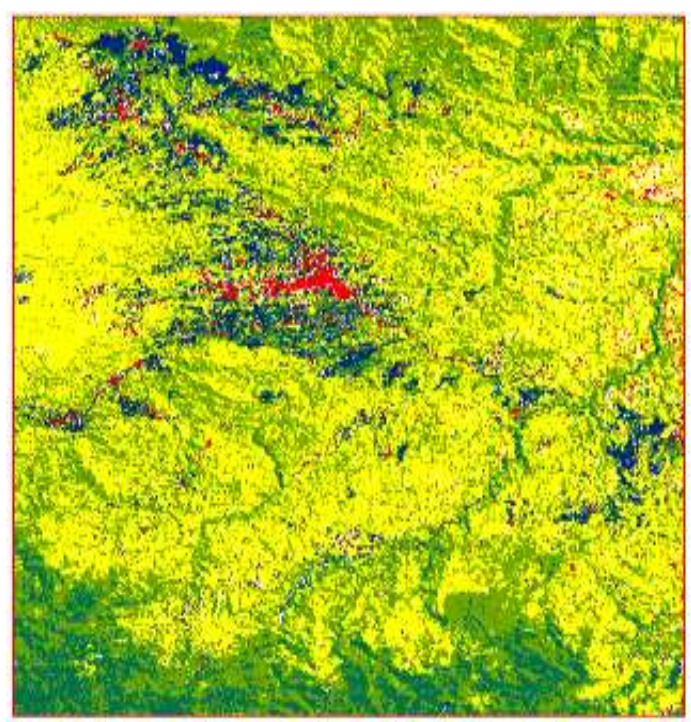

Gambar 10. Peta Tutupan Lahan TNBBS Tahun 2018

e. Perubahan Luas Tutupan Lahan

Perubahan luas tutupan lahannya dihitung dengan menggunakan software Microsoft Excel, setelah itu dicari perubahan luas antar seri tahun yaitu tahun 2015 dengan 2016, 2016 dengan 2017 dan 2017 dengan 2018. Berikut ini diagram perubahan tutupan lahan tahun 2015, 2016, 2017 dan 2018 di kota Pagar Alam, Taman Nasional Bukit Barisan Selatan.

e.1.Perubahan penutupan lahan kurun waktu 2015-2016

Tabel 5. Perubahan Luas Tutupan Lahan Tahun 2015-2016

\begin{tabular}{|c|c|c|c|r|}
\hline \multirow{2}{*}{ No } & \multirow{2}{*}{$\begin{array}{c}\text { Tutupan } \\
\text { Lahan }\end{array}$} & \multicolumn{3}{|c|}{ Luas (Ha) } \\
\cline { 3 - 5 } 1 & $\mathbf{2 0 1 5}$ & $\mathbf{2 0 1 6}$ & Perubahan \\
\hline 1 & Pemukiman & 959,53 & $1.005,99$ & 46,46 \\
\hline 2 & $\begin{array}{c}\text { Lahan } \\
\text { Terbuka }\end{array}$ & $2.270,91$ & $1.717,94$ & $-552,97$ \\
\hline 3 & Pertanian & $4.469,04$ & $3.202,34$ & $-1.266,7$ \\
\hline 4 & $\begin{array}{c}\text { Rumput / } \\
\text { semak }\end{array}$ & $27.616,29$ & $32.117,48$ & $4.501,19$ \\
\hline 5 & $\begin{array}{c}\text { Vegetasi } \\
\text { sedang }\end{array}$ & $18.926,99$ & $17.608,48$ & $-1.318,51$ \\
\hline 6 & $\begin{array}{c}\text { Vegetasi } \\
\text { tinggi }\end{array}$ & $9.469,65$ & $8.060,18$ & $-1.409,47$ \\
\hline \multicolumn{2}{|c|}{ Total Luas } & $63.712,41$ & $63.712,41$ & \\
\hline
\end{tabular}

Keterangan: tanda - menunjukkan penurunan e.2. Perubahan penutupan lahan kurun waktu 2016-2017

Tabel 6. Perubahan Luas Tutupan Lahan Tahun 2016-2017

\begin{tabular}{|r|c|c|c|r|}
\hline \multirow{2}{*}{ No } & \multirow{2}{*}{$\begin{array}{c}\text { Tutupan } \\
\text { Lahan }\end{array}$} & \multicolumn{3}{|c|}{ Luas (Ha) } \\
\cline { 3 - 5 } & $\mathbf{2 0 1 6}$ & $\mathbf{2 0 1 7}$ & Perubahan \\
\hline 1 & Pemukiman & $1.005,99$ & $1.084,84$ & 78,85 \\
\hline 2 & $\begin{array}{c}\text { Lahan } \\
\text { terbuka }\end{array}$ & $1.717,94$ & $3.158,30$ & $1.440,36$ \\
\hline 3 & Pertanian & $3.202,34$ & $2.009,32$ & $-1.193,02$ \\
\hline 4 & $\begin{array}{c}\text { Rumput / } \\
\text { semak }\end{array}$ & $32.117,48$ & $35.199,32$ & $3.081,84$ \\
\hline 5 & $\begin{array}{c}\text { Vegetasi } \\
\text { Sedang }\end{array}$ & $17.608,48$ & $15.519,14$ & $-2.089,34$ \\
\hline 6 & $\begin{array}{c}\text { Vegetasi } \\
\text { tinggi }\end{array}$ & $8.060,18$ & $6.741,49$ & $-1.318,69$ \\
\hline \multicolumn{2}{|c|}{ Total Luas } & $63.712,41$ & $63.712,41$ & \\
\hline
\end{tabular}

Keterangan: tanda - menunjukkan penurunan

e.3. Perubahan penutupan lahan kurun waktu 2017-2018

Tabel 7. Perubahan Luas Tutupan Lahan Tahun 2017-2018

\begin{tabular}{|c|c|c|c|c|}
\hline \multirow{2}{*}{ No } & \multirow{2}{*}{$\begin{array}{c}\text { Tutupan } \\
\text { Lahan }\end{array}$} & \multicolumn{3}{|c|}{ Luas (Ha) } \\
\hline & & 2017 & 2018 & Perubahan \\
\hline 1 & Pemukiman & $1.084,84$ & $1.158,97$ & 74,13 \\
\hline 2 & $\begin{array}{c}\text { Lahan } \\
\text { terbuka }\end{array}$ & $3.158,30$ & $1.765,91$ & $-1.392,39$ \\
\hline 3 & Pertanian & $2.009,32$ & $3.725,87$ & $1.716,55$ \\
\hline 4 & $\begin{array}{c}\text { Rumput / } \\
\text { semak }\end{array}$ & $35.199,32$ & $29.449,20$ & $-5.750,12$ \\
\hline 5 & $\begin{array}{l}\text { Vegetasi } \\
\text { sedang }\end{array}$ & $15.519,14$ & $22.120,26$ & $6.601,12$ \\
\hline 6 & $\begin{array}{c}\text { Vegetasi } \\
\text { tinggi }\end{array}$ & $6.741,49$ & $5.492,20$ & $-1.249,29$ \\
\hline \multicolumn{2}{|c|}{ Total Luas } & $63.712,41$ & $63.712,41$ & \\
\hline
\end{tabular}

Keterangan: tanda - menunjukkan penurunan

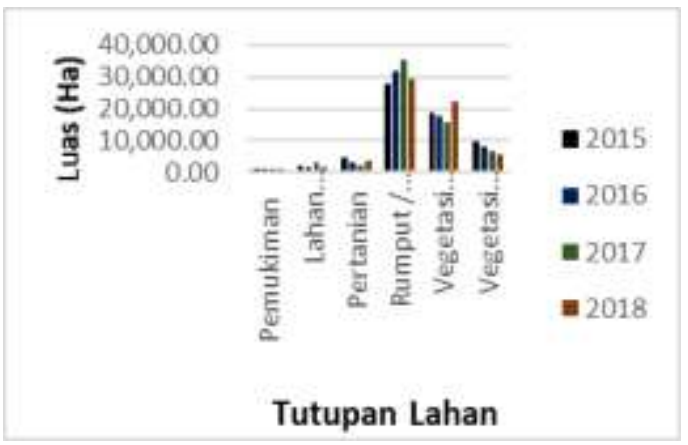

Gambar 11. Diagram Perubahan Tutupan Lahan TNBBS Tahun 2015, 2016, 2017 dan 2018 


\section{PENUTUP}

a. Kesimpulan

Berdasarkan penelitian analisis perubahan tutupan lahan dengan metode maximum likelihood classification di Taman Nasional Bukit Barisan Selatan yang telah dilakukan dapat diperoleh kesimpulan sebagai berikut:

1. Perubahan luas tutupan lahan dari tahun 2015 sampai 2018 yang paling signifikan adalah peningkatan luas pemukiman sebesar $0,32 \%$ dan penurunan luas vegetasi tinggi (kawasan hutan) hingga 7,99\%. Lahan terbuka mengalami penurunan luas $0,79 \%$, lahan pertanian mengalami penurunan hingga $1,12 \%$, tutupan lahan berupa rumput/semak meningkat hingga 4,58\% dan tutupan lahan vegetasi sedang meningkat hingga $5,03 \%$.

2. Kecenderungan perubahan tutupan lahan dari kurun waktu 2015-2018 yaitu tutupan lahan berupa vegetasi tinggi (hutan) semakin berkurang di kawasan hutan Gunung Patah seiring dengan semakin bertambahnya tutupan lahan vegetasi sedang dan lahan rumput/semak, begitu pula dengan tutupan lahan tanah terbuka semakin jarang ditemukan karena semakin bertambahnya permukiman didaerah penelitian terutama kawasan Pagar Alam dan di kawasan Jerai serta Panjar Bulan. Penyebab terjadinya perubahan tutupan lahan dikarenakan adanya kegiatan manusia (konversi lahan) seperti pembukaan lahan untuk dijadikan lahan pertanian, perkebunan maupun lahan pemukiman.

b. Saran

Beberapa saran untuk peningkatan kualitas dalam penelitian tutupan lahan dengan metode penginderaan jauh adalah sebagai berikut:

1. Pembuatan training area dalam klasifikasi terbimbing perlu dilakukan secara teliti agar hasil yang diperoleh juga maksimal, semakin kecil area dan spesifik dalam pembuatan training area akan menghasilkan klasifikasi yang lebih detail.

2. Melakukan perbandingan lain dengan menggunakan algoritma klasifikasi yang berbeda.

3. Pendekatan MLC perlu diterapkan pada citra yang memiliki resolusi tinggi untuk menguji kemampuan dalam mendapatkan informasi mengenai tutupuan lahan atau penggunaan lahan.

\section{REFERENSI}

[1]. Sacafirmansyah, 2006, "Taman Nasional Bukit Barisan Selatan", https://sacafirmansyah.wordpress.com/200 6/11/14/taman-nasional-bukit-barisanselatan/, tanggal akses 12 Juni 2020.

[2]. CNN Indonesia, 2019, "Rentetan Kemunculan Harimau dan Kecemasan Warga Sumsel", https://www.cnnindonesia.com/nasional/20 191205070523-20-454294/rentetankemunculan-harimau-dan-kecemasanwarga-sumsel.

[3]. M. Rusdi, 2005, "Perbandingan Klasifikasi Maximum Likelihood Dan Object Oriented Pada Pemetaan Tutupan/Penggunaan Lahan [Tesis]", Institut Pertanian Bogor, Bogor.

[4]. B. Mentari, 2013, "Identifikasi Karakteristik Dan Pemetaan Klasifikasi Tutupan Lahan Menggunakan Citra Landsat 8 (OLI) Di Kabupaten Bogor", Institut Pertanian Bogor. Bogor.

[5]. L. Wartika, T. Hariyanto, 2013, "Evaluasi Kesesuaian Tutupan Lahan Menggunakan Citra ALOS AVNIR-2 Tahun 2009 Dengan Peta RTRW Kabupaten Sidoarjo Tahun 2007". Jurnal Teknik Pomits. Institut Teknologi Sepuluh Nopember (ITS), Surabaya.

[6]. T. M. Liliesand, R. W. Kiefer, 1997, "Pengginderaan Jauh dan Interpretasi Citra", Terjemahan dari: Remote Sensing dan Image Interpretation, Penerjemah: Dulbahri, Prapto. S, Hartono, Suharyadi, Yogyakarta (ID): Gadjah Mada University Press.

[7]. J. A. Howard, 1996, "Penginderaan Jauh Untuk Sumberdaya Hutan (teori dan Aplikasi)", Gadjah Mada University Press, Bulaksumur, Yogyakarta.

[8]. C. P. Lo, 1996, "Pengindraan Jauh Terapan", Penerjemah: Bambang Purbowaseso, Universitas Indonesia Press, Jakarta.

[9]. NASA (US), 2011, "Landsat Data Continuity Mission.

[10]. T. M. Lillesand, R. W. Kiefer, 1994, "Remote Sensing and Image Interpretation", University of WisconsinMadison. John Wilwy \& Sons Inc., New York, United States.

[11]. I. N. S. Jaya, 1997, "Penginderaan Jauh Satelit Untuk Kehutanan", Laboratorium Inventarisasi Hutan Jurusan Manajemen Hutan Fakultas Kahutanan Institut Pertanian Bogor, Bogor.

[12]. E. Prahasta, 2008, "Remote Sensing: Praktis Pengindraan Jauh \& Pengolahan Citra Digital Dengan Perangkat Lunak ER 
Maper", Bandung : Informatika.

[13]. D. Lu, P. Mausel, M. Batistella, and E. Moran, 2003, "Comparison Of Land-Cover Classification Methods In The Brazilian Amazon Basin". Anchorage. Alaska. 